\title{
Seismic safety evaluation of power transformer based on response spectrum method
}

\author{
Chun $\mathrm{Li}^{1, \text { a }}$, Deping Yang ${ }^{2, \mathrm{~b}}$ \\ ${ }^{1}$ Universal Plaza, Jiuxianqiao Lu 10, Chaoyang District, Beijing 100015, P.R.China \\ ${ }^{2}$ No. 1 Huayannancun Yuqingsi, Zhongliangshan, Chongqing 400052, P.R. China \\ aViki-Chun.Li@cn.abb.com, ${ }^{\mathrm{b}}$ Bengt-DePingYang@cn.abb.com
}

Keywords: Seismic safety, power transformer, response spectrum method, mechanical strength

\begin{abstract}
Power transformers are key components in power distribution systems and ensuring transformer do not be destroyed in the earthquake is critical to the safe operation of power transmission grid. Finite element analyses of power transformer under the earthquake, dead load and wind load are described in this article. The simulation results show that the structure could resist to seismic load and wind load according to GB 50260-2013.
\end{abstract}

\section{Introduction}

Power transformers are one of the most important equipment in substations, however sometimes they might be seriously damaged in strong earthquake especially the porcelain bushing often be occurred the root fracture failure.

The present calculating methods for seismic resistant are: static method, spectrum response and step-by-step integration. The concept of the 'response spectrum' was applied in design requirements in the mid- $20^{\text {th }}$ century; it comes into widespread use as the primary theoretical tool in earthquake engineering in the 1970s when strong-motion accelerograph data became widely available. The Spectrum response is the dynamic analysis method in consideration of both structure dynamic performances and movements of the ground, the time consume of computation is being much saved due to its simple theory.

\section{Finite element analysis}

\section{FE model creation}

The geometry model of power transformer should be simplified before the finite element model creation. Many elements, which are not structural ones and have non business with the vibration, have been omitted to simplify the analysis. However, their mass are still kept in the finite element model as non-structural mass.

Before the nonlinear finite element analysis, it is necessary for the model to be discretized. The Figure.1 showed how the geometric model was meshed. To mesh the model, linear quadrilateral element S4R, linear line element of type B31 and linear hexahedral elements of type C3D8R have been used.

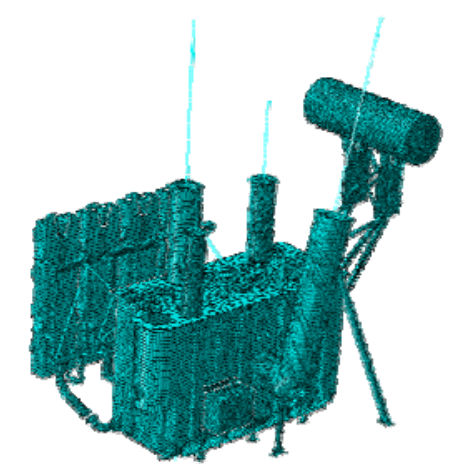

Figure 1 Shell-beam combined FE model of the transformer 


\section{Boundary and load}

There are four load applied to the transformer, gravity, hydrostatic pressure, wind load and Seismic load. The gravity is related to the density of the material which is record in the Table 1.

Table.1 Material parameter

\begin{tabular}{|c|c|c|c|}
\hline Material properties & Young's Modulus (Gpa) & Posson's ratio & Density (Kg/m3) \\
\hline Q345 steel & 210 & 0.3 & 7850 \\
\hline
\end{tabular}

The hydrostatic pressure is caused by the oil stored in the transformer. As the inner wall of container was pressed on account of the oil density and the distance to the free surface, the press can be calculated by equation 1 :

$$
\mathrm{p}=\rho^{*} \mathrm{~g} * \mathrm{~h}
$$

where $\mathrm{p}$ means the hydrostatic pressure in different places, $\rho$ means the oil density and $\mathrm{h}$ means the distance between the location and the free surface. In this paper the height of the surface is $9860 \mathrm{~mm}$ and $100 \mathrm{~mm}$ away from the top of the oil tank.

From the data of the environment offered by the customer, the speed of the wind applied to the transformer is $27.6 \mathrm{~m} / \mathrm{s}$ whose stress is equivalent to $476 \mathrm{~Pa}$. Based on it the biggest windward side was applied $476 \mathrm{~Pa}$ while the stress applied to the radiator was one third of it $(158.7 \mathrm{~Pa})$.

Same as the wind load, from the data of the environment offered by the customer, earthquake that the transformer should be suffered would be magnitude 5 while the location the transformer would be installed is type $I_{1}$. Take the $<$ GB50260-2013 $>$ as reference, the Site adjustment coefficient of the seismic influence coefficient is 0.80 . The curve of the seismic response spectrum that finally used is shown in Figure.2.

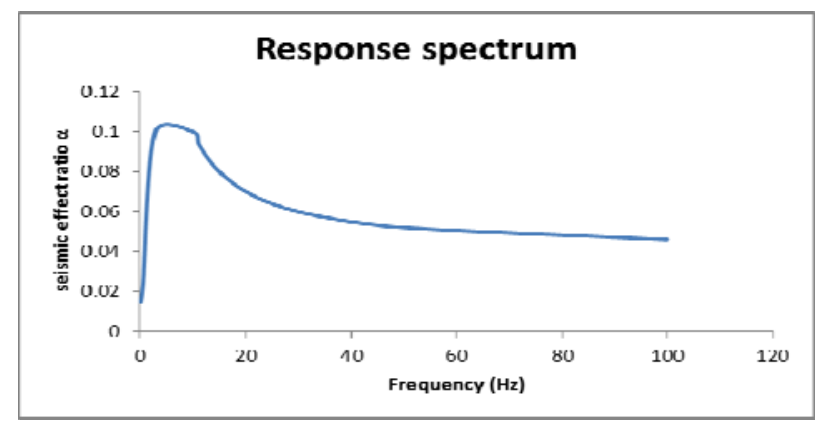

Figure 2 Seismic response spectrum according to GB 50260-2013

The boundary of the transformer is that all freedom of bottom surface of transformer was constrained.

\section{Mode analysis}

As the vibration analysis needs the natural frequency and the modal of the structure, the mode analysis is necessary. The results of the modal analysis are shown in table.2. It can be informed from the table that the effective modal mass alone the three axis are all over the $95 \%$ of the total mass to meet the requirement which make the result convincing.

Table.2 Frequency and the effective modal mass of the main modals

\begin{tabular}{|c|c|c|c|}
\hline \multirow{2}{*}{ modal } & \multicolumn{3}{|c|}{ Effective modal mass } \\
\cline { 2 - 4 } & $\mathrm{X}$ axis $(\mathrm{t})$ & $\mathrm{Y}$ axis $(\mathrm{t})$ & $\mathrm{Z}$ axis $(\mathrm{t})$ \\
\hline proportion & $99.04 \%$ & $99.79 \%$ & $95.13 \%$ \\
\hline
\end{tabular}

\section{Seismic spectrum analysis}

In this part there are six elements have been analyzed under the environment of earthquake. Here are the analysis results showing the stress distribution of stress in each component. 


\section{1) Fuel tank assembling}

The analysis of the fuel tank and cover plate are shown in Figue.3.

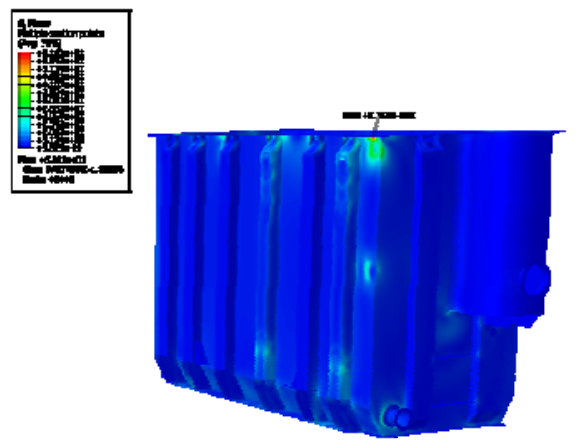

(a) Fuel tank

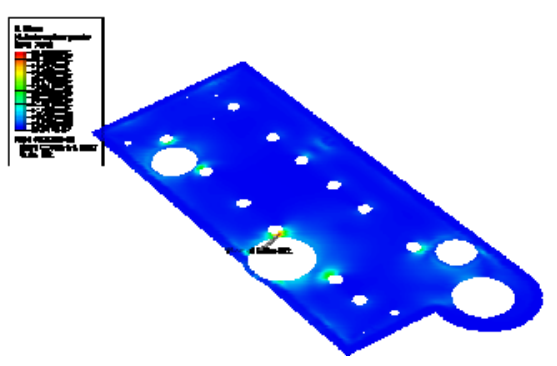

(b) cover plate

Figure. 3 Von Mises stress distribution of the fuel tank and cover plate

It can be informed that the maximum value of Von Mises stress in the fuel tank is 62Mpa and in the cover plate is $56 \mathrm{MPa}$, which are lower than the yield limit of the Q345 steel (345MPa). The safety factor based on the data mentioned above is 5.56 for fuel tank assembling so that the fuel tank assembling can meet the requirement.

\section{2) Oil tank}

The analysis of the oil tank is shown in Figue.4.

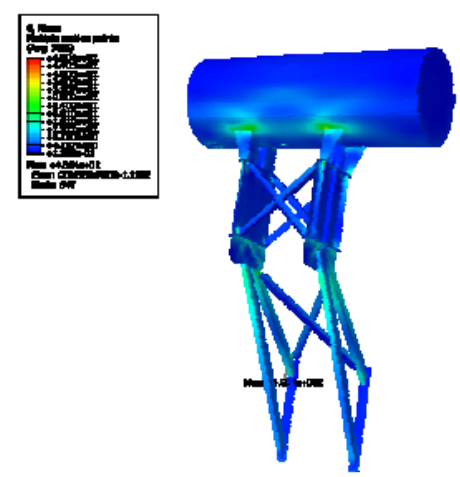

Figure. 4 Von Mises stress distribution of the oil tank

It can be informed that the biggest Von Mises stress in the fuel tank is $48 \mathrm{Mpa}$ while the safety factor is 7.19. Obviously the oil tank can meet the requirement.

\section{3) Lifting pedestal}

The analysis of the lifting pedestal is shown in Figue.5.

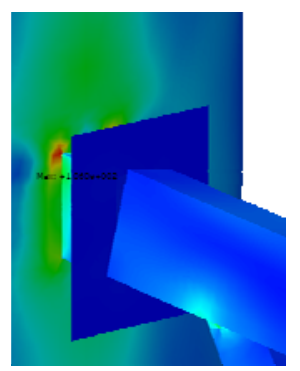

Figure.5 Von Mises stress distribution of the lifting pedestal

It can be informed that the biggest Von Mises stress in the lifting pedestal is 106Mpa while the safety factor is 3.25 . It can be concluded that the lifting pedestal can meet the requirement.

\section{4) Insulating bushings}

The insulating bushings could be simplified as cantilever beam, it is checked by the bending moment if it can support the load caused by the earthquake.

Based on the analysis of the insulating bushings mentioned above, the maximal bending moment and the safety factors are displayed in the table. 3 below. 
Table.3 Maximal bending moment and the safety factors of the bushes

\begin{tabular}{|c|c|c|c|c|c|}
\hline & $\begin{array}{c}\text { bending } \\
\text { component 1 } \\
\left(\mathrm{N}^{*} \mathrm{~mm}\right)\end{array}$ & $\begin{array}{c}\text { bending } \\
\text { component 2 } \\
\left(\mathrm{N}^{*} \mathrm{~mm}\right)\end{array}$ & $\begin{array}{c}\text { Bending } \\
\text { moment } \\
\left(\mathrm{N}^{*} \mathrm{~m}\right)\end{array}$ & $\begin{array}{c}\text { maximum } \\
\text { bending } \\
\text { moment } \\
\left(\mathrm{N}^{*} \mathrm{~m}\right)\end{array}$ & $\begin{array}{c}\text { Safety } \\
\text { factor }\end{array}$ \\
\hline $\begin{array}{c}\text { high voltage bushing } \\
\text { (HV) }\end{array}$ & 8400 & 11500 & 14241 & 74763 & 5.25 \\
\hline $\begin{array}{c}\text { high voltage natural } \\
\text { bushing (HVN) }\end{array}$ & 362 & 347 & 501 & 3528 & 7.04 \\
\hline $\begin{array}{c}\text { Low voltage bushing } \\
\text { (LV) }\end{array}$ & 11400 & 8180 & 14031 & 77880 & 5.55 \\
\hline $\begin{array}{c}\text { low voltage natural } \\
\text { bushing (LVN) }\end{array}$ & 2450 & 2650 & 3609 & 34560 & 9.58 \\
\hline
\end{tabular}

From the Table. 3 it can be concluded that the safety factors of the four bushings are all over 5 , which can fully meet the requirement.

\section{Conclusion}

To analyze the seismic failure mechanism of a certain power transformer that suffered earthquake damage, a finite element model of transformer-bushing system, in check both beam elements and shell elements are combined, in built. Under the input of seismic spectrum according to GB 50260-2013, the analysis on spectrum responses during earthquake is performed by the proposed model, and the seismic responses of the key components in the structure of transformer-bushing system during the earthquake are compared. Analysis results show that this power structure could resist the required seismic load, and the bushings are vulnerable components of power transformers, so in the seismic design, the vulnerability of bushings during earthquake should be take fully into account.

(1) The maximum of transformer is $106 \mathrm{MPa}$ which is about $30 \%$ of material allowable stress that means there are no yield occurred at whole structure of transformer, the safety factor is about 3 .

(2) The maximum reaction moment of bushing is $4000 \mathrm{kNM}$, which is smaller than the permissible bending moment of porcelain bushings that means the deformation of bushings is still elastic deformation and the safety factor is about 5 .

\section{References}

[1] GB 50260-2013 Cod for seismic design of electrical installations.

[2] Institute of electrical and electronics engineers. IEEE Std-693-2005 Recommended practice for seismic design of substation [s]. New York: IEEE Press, 2006.

[3] Zhou Shiping, Transform damage analysis in the 5.12 Wenchuan earthquakes. Hubei power, Vol 32 No.4, 2008.

[4] Zhu Ruiyuan, Shaking table tests of mock transformer-bushing system, Power system technology, Vol37 No 10, 2013.

[5] GuoZhen Yan, study shen yang,Shen Yanggongyedaxue, [D],2004. 